\title{
Treatment strategies for large impacted upper ureteral stones
}

\author{
Eyup Burak Sancak, MD; Alpaslan Akbas, MD
}

Canakkale Onsekiz Mart University, Turkey

\section{CUAJ Letters is an open forum to discuss papers published in CUAJ. Letters are published at the discretion of the editors, and are subject to abridgement and editing for style and content. Letters can be sent to the Editor at journal@cua.org.}

Cite as: Can Urol Assoc J 2016;10(7-8):287.

http://dx.doi.org/10.5489/cuaj.3605

W e read with interest the article by Bozkurt et al in which they compared the outcomes of percutaneous nephrolithotomy (PCNL) and ureteroscopic lithotripsy (UL) to treat large $(\geq 1.5 \mathrm{~cm})$, impacted, upper ureteral stones. ${ }^{1}$

An impacted stone was defined as a stone that did not allow any passage on contrast graphies, stayed at the same localization for more than one month, and resulted in dilation in the collecting system. In some publications, an impacted stone is defined as a stone that cannot be bypassed either by a wire or a catheter. ${ }^{2,3}$ As understood from the definition, impacted stones that do not allow a catheter to pass to the kidneys are frequently encountered. The authors should explain more clearly and carefully whether retrograde catheterization was easily performed in the PCNL group, and if it was not possible, whether additional instrumentation was used and what approach was chosen.

The authors deemed the procedure unsuccessful when the stone could not be reached in a single session and when residual stone $\geq 4 \mathrm{~mm}$ was detected at the one-month postoperative visit. The authors give the success rate for 41
URS patients as $82.3 \%$. However the stone-free rate among these patients is given as $82.9 \%$ and it is stated that three patients could not be reached during URS. The authors need to be more precise about treatment success rate, stonefree situation, and percentages given.

Finally, for all ureter stones included in the study, one of the inclusion criteria was localization of stone between the lower border of L4 spine and ureteropelvic junction. Only a nephroscope was used during PNL treatment. How PNL was performed on a ureteral stone at L4 level is not explained. The treatment method or stone localization in the PNL group needs to be explained more clearly.

Competing interests: The authors declare no competing financial or personal interests.

\section{References}

1. Bozkurt IH, Yonguc T, Arslan B, et al. Minimally invasive surgical treatment for large impacted upper ureteral stones: Ureteroscopic lithotripsy or percutaneous nephrolithotomy? Can Urol Assoc J 2015;9:E122-5. http://dx.doi.org/10.5489/cuai.2280

2. Shao Y, Wang DW, Lu GL, et al. Retroperitoneal laparoscopic ureterolithotomy in comparison with ureteroscopic lithotripsy in the management of impacted upper ureteral stones larger than $12 \mathrm{~mm}$. World J Urol 2015;33:1841-5. http://dx.doi. org/10.1007/s00345-015-1545-0

3. Fam XI, Singam $\mathrm{P}$, $\mathrm{H}_{0} \mathrm{CC}$, et al. Ureteral stricture formation after ureteroscope treatment of impacted calculi: A prospective study. Korean J Urol 2015;56:63-7. http://dx.doi.org/10.4111/ kju.2015.56.1.63

Correspondence: Dr. Eyup Sancak, Canakkale Onsekiz Mart University, Turkey; eyupburaksancak@comu.edu.tr

\section{Author reply}

\author{
Ibrahim Halil Bozkurt, MD; Tarik \\ Yonguc, MD; Ozgu Aydogdu, MD; \\ Tansu Degirmenci, MD
}

Izmir Bozyaka Training and Research Hospital Urology Clinic, Turkey

Cite as: Can Urol Assoc J 2016;10(7-8):287.

http://dx.doi.org/10.5489/cuaj.3884

$\mathrm{t}$ is not a must to pass the catheter into renal pelvis or upper calyx at the

beginning of PCNL. Forceful actions made for passing the catheter behind the stone may lead to additional complications, such as ureteral perforation and hemorrhage, especially in impacted ureteral stones and renal pelvis stones fully obstructing the ureteropelvic junction. In these cases, we prefer to place the ureteral catheter just below the stone and give the contrast material from this site. In extremely rare cases, the contrast material can not pass the stone; in these cases, the initial puncture is performed under ultrasonic guidance.

The percentages in the abstract section were miswritten. However the correct values can be clearly seen in the results section and in Table 1 (82.9\% for ureteroscopic lithotripsy [UL] and $97.8 \%$ for PCNL).

As stated in the manuscript, this is not a randomized study; this is a retrospective study. There may be a selection bias in favour of UL for stones located close to the L4 spine.

Competing interests: The authors declare no competing interests.

Correspondence: Dr. Ibrahim Halil Bozkurt, Izmir Bozyaka Training and Research Hospital Urology Clinic, Turkey; ihalilbozkur†yahoo.com 